\title{
Redox proteomic identification of carbonylated proteins in autism plasma: insight into oxidative stress and its related biomarkers in autism
}

Chengyun Feng ${ }^{2}$, Youjiao Chen ${ }^{1}$, Jintao Pan², Aochu Yang ${ }^{1}$, Li Niu², Jie Min², Xianling Meng ${ }^{2}$, Liping Liao ${ }^{1}$, Kaoyuan Zhang ${ }^{1}$ and Liming Shen ${ }^{1 *}$

\begin{abstract}
Background: Autism is a severe childhood neurological disorder with poorly understood etiology and pathology. Currently, there is no authentic laboratory test to confirm the diagnosis of autism. Oxidative damage may play a central role in the pathogenesis of autism. Present study is an effort to search for possible biomarkers of autism and further clarify the molecular changes associated with oxidative stress that occurs in the plasma of autistic children.

Methods: We performed redox proteomics analysis to compare carbonylated proteins in the plasma of autistic subjects and healthy controls. Immunoprecipitation and Western blot analysis were used to validate carbonylated proteins identified by the redox proteomics.

Results: Protein carbonylation levels in two proteins, complement component C8 alpha chain and lg kappa chain C were found to be significantly increased in autistic patients compared with controls. These two proteins were successfully validated via immunoprecipitation and Western blot analysis.
\end{abstract}

Conclusions: The results further highlight the role of oxidative stress in the pathogenesis of autism and provide some information for the diagnosis and/or monitoring of autism.

Keywords: Autism, Biomarkers, Plasma, Protein carbonylation, Redox proteomics

\section{Background}

Autism spectrum disorders (ASDs) are characterized by social deficits, repetitive/stereotypical behaviors and interests, as well as communication problems [1]. An increase in the prevalence of ASD is being reported worldwide with social, behavioral and economical burdens, and recent epidemiological studies indicated that at least one in every 100 people has some form of autism [2,3]. Even more, autism related disorders are increasing at an alarming rate and have now affected $2 \%$ of US

\footnotetext{
*Correspondence: slm@szu.edu.cn

${ }^{1}$ College of Life Sciences and Oceanography, Shenzhen University,

Shenzhen 518060, People's Republic of China

Full list of author information is available at the end of the article
}

school-aged children [4]. The boys had a higher prevalence than girls and the boy to girl's ratio on average is 4.3:1 [5].

ASD is considered as a multi-factorial disorder, influenced by genetic, neurological, environmental and immunological factors. Biomolecular evidence points to complex gene-environmental interactions in ASDs. A significant contribution from environmental factors in determining ASD risk is consistent with both the rapid increase in ASD incidence and the clinical heterogeneity which are hallmark of this neurodevelopmental disorder [6]. Several biochemical processes are associated with ASDs. These include oxidative stress, decreased methylation capacity, limited production of glutathione, mitochondrial dysfunction, intestinal dysbiosis, increased toxic metal burden and various immune abnormalities 
[7]. However, up to now, the etiology of autism is not fully understood, there are no medications prescribed for the core symptoms of autism. But some behavioral treatments are available to improve core and associated symptoms of autism, particularly when initiated at an early stage [8]. Regretfully, so far, no biomarkers for diagnosis or prediction of autism have been validated [9]. Thus, there is an increasing demand for finding biomarkers of autism as they could help to identify children with ASD as early as possible [10].

Human blood is a rich source for biomarker discovery. Proteomics provides the opportunity to analyze and identify biomarkers for neuropsychiatric disorders including ASD. However, in past years, very few studies are reported on proteomics based research on autism, and these were quantitative proteomics studies in which differential expression of proteins were identified [11]. Besides detecting the changes in protein concentration, post-translational protein modifications (PTMs) have contributed significantly to the identification of macromolecular biomarkers of biological processes [12]. Using a redox proteomics approach, some oxidatively modified proteins have been identified in plasma [13], cerebrospinal fluid [14] and brain of Alzheimer's disease (AD) patients [15]. The existing evidences support the role of oxidative stress in the pathogenesis of autism [16]. Increased oxidative stress could lead to protein oxidation, resulting in 3-nitrotyrosine (3NT) and protein carbonyl formation. Protein carbonyls (PCO) and 3NT-modified proteins are considered as markers of protein oxidation. Interestingly, $3 \mathrm{NT}$ have been found to be elevated in plasma [17], cerebellum brains of children with ASD [18]. However, at present, no study focused on redox proteomics study of plasma proteins in autism. In order to understand the role of oxidative stress in the pathophysiology of autism and search possible protein biomarkers with diagnostic utility, we carried out redox proteomics analysis to compare protein profiles of plasma from children with autism and healthy controls in this study. To best of our knowledge, this is the first report applying redox proteomics to plasma from children with autism compared to healthy subjects.

\section{Methods}

\section{Plasma samples}

Twelve male and three female autistic patients (2-6 years old) were selected for sampling from Populations and Family Planning Hospital of Baoan and subjected for comparative autism analysis along with 12 male and 3 female normal control patients of the same age. The study protocol was approved by Human Research Ethics Committees of Populations and Family Planning Hospital of Baoan. The autism was diagnosed by a child neuropsychiatrist based on the criteria of autistic disorders as defined in the Diagnostic and Statistical Manual of Mental Disorder-Fourth Edition (DSM-IV). Participants did not have any physical disabilities, or additional psychiatric or neurological diagnosis or family history of ASD. They were also not taking medications and any dietary supplements. There were no significant differences in the distributions of weight, height or body mass index (BMI) between the autism and the control groups. The experiments were conducted with the written consent of the caretakers of the children under observation according to the guidelines of the Human Research Ethics Committees of Populations and Family Planning Hospital of Baoan. Blood samples $(5 \mathrm{ml})$ were collected in sodium heparin coated plastic tubes in the morning and in the fasting state, and then centrifuged at $3000 \times g$ for $10 \mathrm{~min}$ at room temperature. The supernatants were divided and stored in aliquots at $-80^{\circ} \mathrm{C}$ for further analysis.

\section{Sample preparation}

For redox proteomic analysis, the pooled plasma samples were used. Equal amounts of plasma from 15 autism and 15 healthy controls were pooled, respectively. In order to reduce the sample complexity, the pooled plasma samples were pre-treated with ProteoExtract Albumin/IgG Removal Kit (Calbiochem, Darmstadt, Germany). After high-abundance proteins depletion, the samples were centrifuged at $12,000 \times g$ in Amicon ${ }^{\circledR}$ Ultra Centrifugal Filters ( $3 \mathrm{kDa}$ cut-off, Millipore) and buffer-exchanged with sample buffer (7 M urea, $2 \mathrm{M}$ thiourea, $4 \%(\mathrm{w} / \mathrm{v})$ CHAPS, $2 \%(\mathrm{v} / \mathrm{v})$ immobilized pH gradients (IPG) buffer pH 4-7 NL, $65 \mathrm{mM}$ DTT, $30 \mathrm{mM}$ Tris). To verify the efficiency of immunodepletion, flow-through fraction (depleted serum) and eluted fraction were separated on sodium dodecyl sulfate-polyacrylamide gel electrophoresis (SDS-PAGE) followed by Coomassie brilliantlue staining R-250. All protein samples were stored at $-80{ }^{\circ} \mathrm{C}$ until further analysis and the protein concentration was determined by the Bradford assay.

\section{D-Oxyblot}

PCO were analyzed by 2-DE (two-dimensional gel electrophoresis) plus Western blot analysis (2D-Oxyblot) using the in-strip derivatization technique $[19,20]$. 2-DE was performed as described previously in detail [21]. Each sample was electrophorized in duplicates, after running, proteins in one gel were silver stained, and in another gel was transferred to polyvinylidene difluoride (PVDF) membrane. The membranes were subsequently blocked, washed and incubated overnight at $4{ }^{\circ} \mathrm{C}$ for immunoblotting with anti-DNP (dinitrophenylhydrazone) antibody (1:1000 dilution, Sigma-Aldrich Co., St. Louis, USA). The blots were then washed with PBS 
(phosphate-buffered saline) and $0.2 \%(\mathrm{v} / \mathrm{v})$ Tween-20 (PBST) and incubated with the goat anti-mouse IgG/ HRP conjugate (1:5000 dilution, Abmart Inc, Shanghai, China). After three washes with PBST, the signal was detected with an ECL kit (Pierce ECL detection kit, Thermo Fisher Scientific Inc., Rockford, USA). The emitted chemiluminescent signals were detected using a digital imaging system (Kodak Image Station 4000MM, Carestream Health, Inc., Rochester, NY, USA). Silverstained gels were imaged using the proXPRESS 2D imaging system (PerkinElmer, Waltham, MA, USA). The intensity of carbonylated spots on 2D-Oxyblots was normalized versus their respective spots visualized on silver stained gels. The spots showing significant differences in specific carbonylation levels between autism and control using Student's $t$ test statistical analysis $(p<0.05)$ were chosen for identification. For protein identification, the spots of interest were excised manually from the silverstained gels and tryptic in-gel digestion was performed as described previously [22]. Mass spectroscopy analysis was performed on a 5800 MALDI TOF/TOF mass spectrometer (AB Sciex, Foster City, CA, USA) [21, 22] or Triple TOF 5600 system (AB Sciex) [23].

Immunoprecipitation and post-Western blot derivatization To confirm the redox proteomic results, the carbonyl levels of C8A and IGKC were detected by post-Western blot derivatization after immunoprecipitation [20]. The experiment was replicated three times. For each time, three age-and sex-matched different subjects were randomly chosen from the total 15 of each group, and their original individual plasma frozen aliquots were used. C8A and IGKC were immunoprecipitated using C8A antibody (Santa Cruz Biotechnology Inc., Santa Cruz, CA, USA) and IGKC antibody (Bioss Inc., Beijing, China), respectively, and then probed for protein carbonyl levels. Protein samples $(300 \mu \mathrm{g})$ were incubated overnight at $4{ }^{\circ} \mathrm{C}$ with the respective antibodies. Protein A and G plus-agarose beads (Santa Cruz Biotechnology Inc.) were added, and the mixture was incubated for $3 \mathrm{~h}$, and then washed with lysis buffer three times. The beads were resuspended in SDS loading buffer and boiled for $5 \mathrm{~min}$. After centrifugation, the supernatant was collected, separated by SDS-PAGE, and transferred to PVDF membranes. The membranes were equilibrated in solution A (20\% (v/v) methanol: $80 \%(\mathrm{v} / \mathrm{v})$ PBST) for $5 \mathrm{~min}$, followed by incubation in $2 \mathrm{~N} \mathrm{HCl}$ for $5 \mathrm{~min}$. The proteins on blots were then derivatized in solution $\mathrm{B}$ (0.5 mM DNPH (2,4-dinitrophenylhydrazine) in $2 \mathrm{~N}$ $\mathrm{HCl}$ ) for $5 \mathrm{~min}$ [24]. The membranes were washed three times in $2 \mathrm{~N} \mathrm{HCl}$ for 5 min each and then five times with $50 \%$ methanol and two times with PBST each for $5 \mathrm{~min}$. The immune complexes were revealed by enhanced chemiluminescence as described above. The data are presented as mean \pm standard error of the mean (SEM) and statistical analyses were performed by two-tailed Student's $t$ test. $p$ values $<0.05$ were considered statistically significant.

\section{Results}

Immunodepletion of high abundance plasma proteins

The most challenging obstacle to develop blood-based biomarkers is the massive dynamic range of proteins in blood, spanning up to 12 orders of magnitude [25]. In this study, prior to proteomic analysis, plasma samples were processed using the ProteoExtract Albumin/IgG Removal Kit, which selectively removes albumin and immunoglobulin (IgG) from the plasma sample. The protein patterns of plasma samples before and after depletion were visualized on SDS-PAGE gels and shown in Fig. 1. Consistent with the user manual, after depletion of high abundance proteins as compared to the crude plasma sample, more protein bands were observed in the lane of depleted plasma, suggesting that the low and medium abundance proteins could be enriched by affinity depletion of abundant proteins. However, the results also showed that most of albumin and IgG were removed except few of them (Fig. 1), which is consistent with manufacturer's instruction and previous study [26].

\section{Redox proteomics analysis of children with autism and healthy control plasma samples}

Using a redox proteomics approach, after isoelectric focusing (IEF), IPG strips were derivatized with DNPH, which were then separated by SDS-PAGE gel and detected by Western blot analysis with anti-DNP antibody. Hence the carbonylated proteins were identified. Figure 2 shows representative 2D gels with silver staining of total proteins and the corresponding 2D-Oxyblots for carbonylated proteins in the plasma of autistic children and controls. Through image comparison, three proteins were found to be significantly elevated in carbonyl levels $(p<0.05)$ and considered as carbonylated proteins in children with autism (Fig. 2b). These were identified by mass spectrometry analysis. These proteins were complement component $\mathrm{C} 8$ alpha chain $(\mathrm{C} 8 \mathrm{~A})$ and Ig kappa chain $\mathrm{C}$ (IGKC). The relevant information of these proteins is listed in Table 1 and indicated by arrows and numbers in Fig. 2. The spots 1 and 2 were identified as the same protein (Table 1; Fig. 2), i.e., IGKC. No significant differences were observed in their protein expression levels between patients and the healthy controls (Fig. 2a).

\section{Validation of redox proteomics results}

To validate redox proteomics results, the carbonyl levels of C8A and IGKC were detected. Samples were 


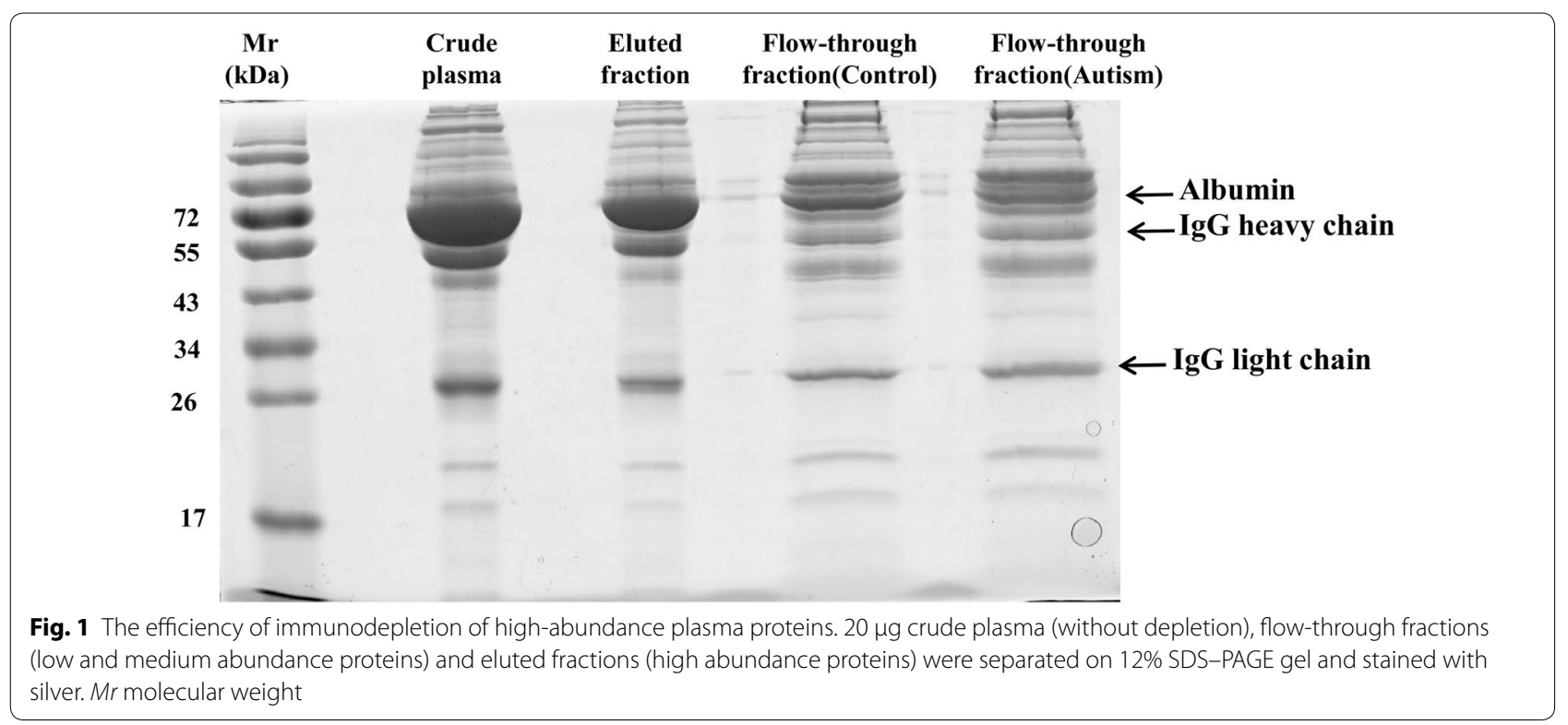

post-derivatized with DNPH on a membrane and probed with anti-DNPH antibody to identify the carbonylated proteins. Consistent with redox proteomics results, the carbonyl levels of C8A and IGKC were significantly higher in the plasma of children with autism compared with the healthy control subjects (Fig. 3, $p<0.05$ ).

\section{Discussion}

Autism is a severe developmental disorder with poorly understood etiology. Oxidative stress is documented and independently confirmed to be increased in children with autism by various methods [27]. Increased excretion of oxidative stress biomarkers and reduced levels of antioxidants have been reported in autism [16, 27-29]. The brain is highly vulnerable to oxidative stress due to its limited antioxidant capacity, higher energy requirement, and higher amounts of lipids and iron [30]. Children are more vulnerable than adults to oxidative stress because of their naturally low glutathione levels from conception through infancy $[27,31]$. Oxidative stress could result in protein oxidation, however, the relation between carbonylated proteins and autism has not been investigated yet.

Here, we applied redox proteomics approaches to analyze the carbonylated proteins in the plasma of autistic patients. The results revealed that the carbonyl levels of two proteins (i.e., C8A and IGKC) were significantly increased in autistic subjects compared with age-matched controls. C8A is involved in complement and coagulation cascades and IGKC involved in immune response. Interestingly, complement active and immune dysfunction has been related to the pathogenesis of autism [32, 33]. The complement system comprises a group of proteins which, when activated, provide one of the first lines of defense by promoting lysis and removal of invading microbes [34]. The complement system may also be involved in cellular apoptosis in brain and peripheral differences of immune molecules that could impact indirectly on the developing brain in autism [32]. Comparison with healthy controls, several up-regulated complement proteins have been reported in the serum of ASD [32], including complement factor $\mathrm{H}$ related protein (FHR1), complement $\mathrm{C} 1 \mathrm{q}$ and complement factor I (CFI). Increases in three peptides that correspond to $\mathrm{C} 3$ complement protein fragments were identified in the plasma of children with ASD [33]. Here, C8A showing significantly increased carbonyl levels in the plasma from autistic children compared with controls, demonstrating and supporting the option that complement system may be involved in the pathophysiology of autism [32, 33]. Generally, oxidative modification of proteins/enzyme leads to dysfunction or decreased activity, but the effect of oxidatively modified C8A is not clear and require further study.

Immune dysfunction such as immune cell dysfunction, imbalance of serum IgGs and cytokines has been proposed as a potential mechanism for ASD [35-37]. Decreased levels of IgM and IgG classes of IgG have been observed in a previous study, with lower levels found to correlate with more aberrant behaviors in ASD [36]. Studies showed that higher frequency of autoimmune disorders, such as rheumatoid arthritis in families with autistic probands than in those of healthy control subjects [27]. In this study, two protein spots were identified as IGKC. As the plasma used were obtained from 2 to 6 years old children, implying that IgG is prone to be 


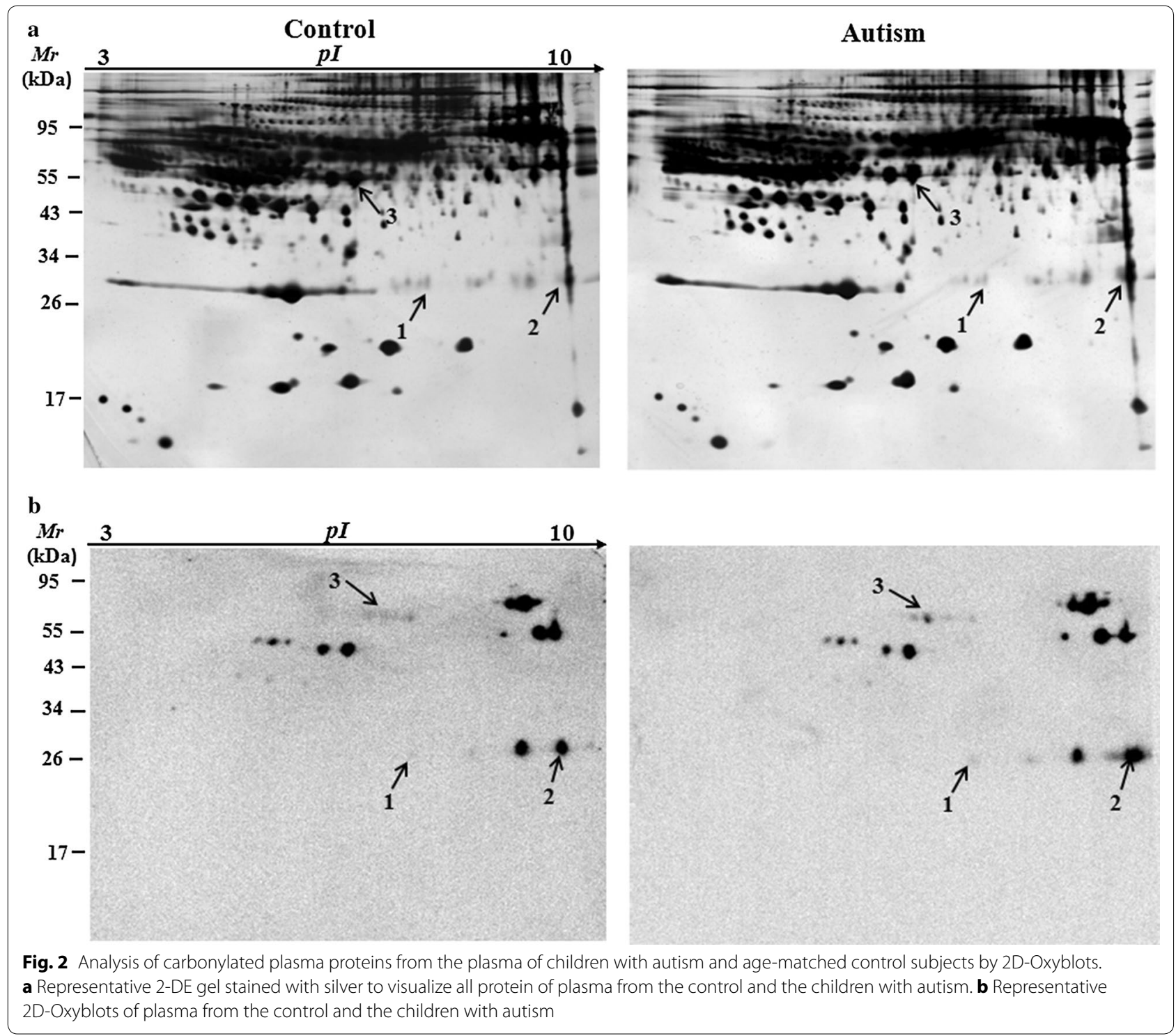

Table 1 Oxidatively modified proteins identified in the plasma of children with autism compared to the age matched controls

\begin{tabular}{lllllccc}
\hline Spot & Protein identified & Gene name & $\begin{array}{l}\text { SwissProt } \\
\text { accession }\end{array}$ & MW(kDa)/pl & Protein Score & Peptides matched $^{\mathbf{a}}$ & Oxidation fold $^{\mathbf{b}}$ \\
\hline 1 & Ig kappa chain C & IGKC & P01834 & $11.8 / 5.58$ & 2332 & $61(54)$ & 2.45 \\
2 & Ig kappa chain C & IGKC & P01834 & $11.8 / 5.58$ & 184 & $3(3)$ & 2.06 \\
3 & $\begin{array}{l}\text { Complement component C8 } \\
\text { alpha chain }\end{array}$ & C8A & P07357 & $66.8 / 6.07$ & 1317 & $43(32)$ & 2.18 \\
\hline
\end{tabular}

\footnotetext{
a Peptides matched by mass fingerprinting
}

b $p<0.05$ versus the control

oxidized. This is consistent with previous studies showing that IgG and especially its Fc portion was quite vulnerable to reactive oxygen species [38]. Elevated levels of oxidized IgG have been observed in various diseases, including AD [14], rheumatoid arthritis [39], end-stage renal disease patients [40] and type 1 diabetes mellitus etc. [41, 42]. Very recently, five IgG proteins including Ig gamma-2B chain $\mathrm{C}$ region (IGH-3), Ig lambda-2 chain 


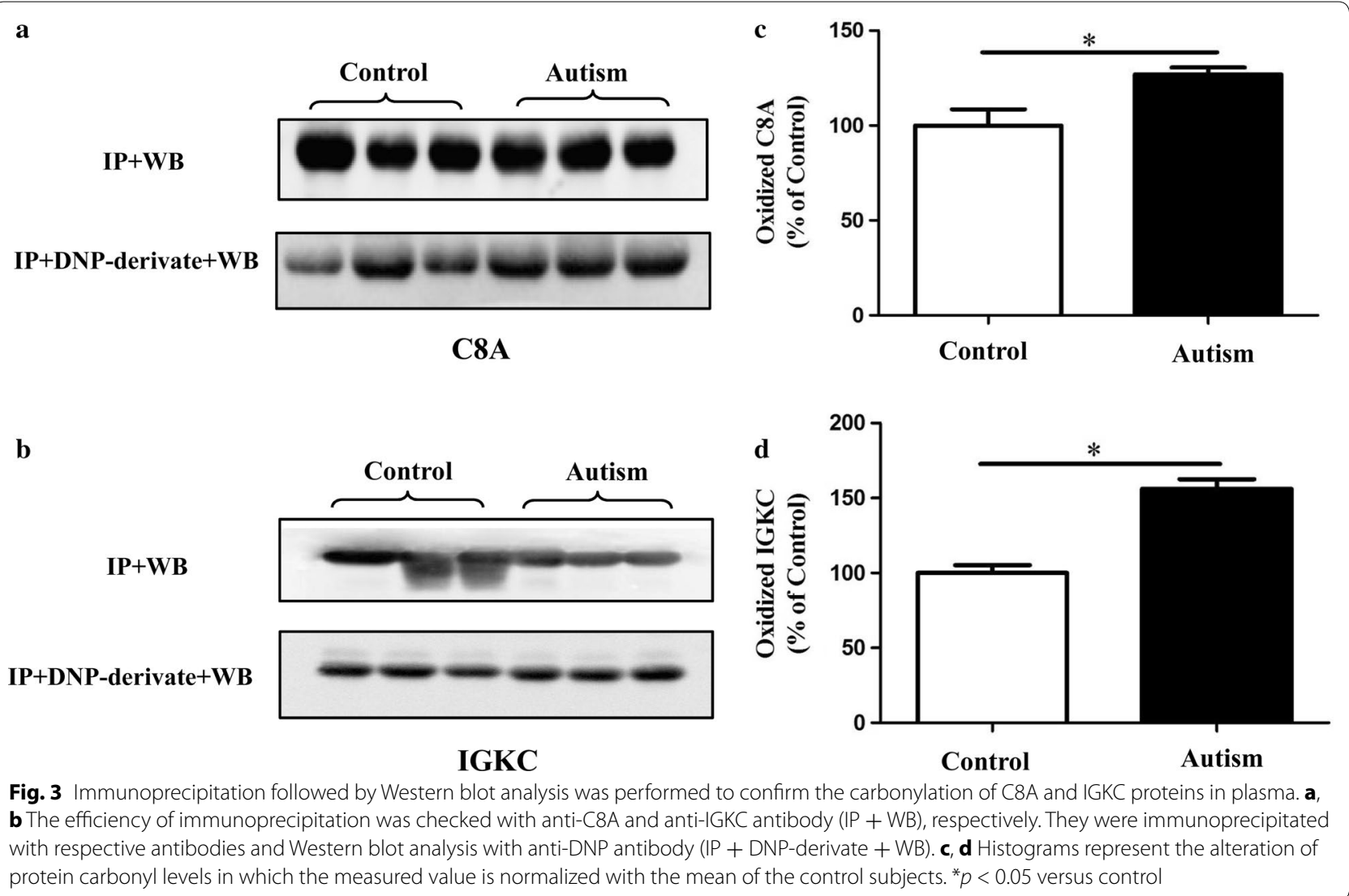

$\mathrm{C}$ region (IGLC2), IGKC and Ig kappa chain $\mathrm{V}-\mathrm{V}$ region HP R16.7 were identified as carbonylated proteins in the serum of 3 -month-old triple transgenic AD mice $(3 \times$ Tg-AD mice) [43].

IgG is the high abundant plasma protein in the plasma, which was identified as oxidatively modified protein. This shows that a relative amount of IgG was still present in the IgG-depleted plasma samples [26]. Oxidative stress alters its structure and may result in modification of its biological properties. In vitro study has demonstrated that oxidation of IgG impairs its ability to bind to macrophage Fc receptors [44] and may lead to decrease its anti-inflammatory properties. Likewise, a previous study proposed that conformational changes in IgG due to oxidative stress could render it immunogenic, resulting in induction of autoantibodies in type 1 diabetes patients [42]. Thus, we speculate that oxidative stress lead to protein oxidation modifications being one of the factors inducting autoimmune response in autistic patients.

It is necessary to point out that this study is a preliminary investigation. As oxidative stress has been related to various diseases, and thus may decrease the specificity of carbonylated protein as disease markers. However, based on the complexity of autism pathogenesis, a combination of multiple markers could be a more powerful approach to diagnose this disease [16]. Even more, analyses of both protein expression level and oxidative modification (carbonylation) could increase specificity of the marker [13]. Thus, the oxidatively modified proteins may also be considered as one type of biomarkers in blood for autism diagnosis, and/or combined with differentially expressed proteins between autistic patients and healthy subjects. In addition, the results would have been enhanced had there been another non-ASD control group with developmental delays and/or other disorders of childhood. Clearly, this needs to further investigate. Moreover, this technology and technique may also assist in monitoring disease states like autism and responses to treatment in a clinical trial environment.

\section{Conclusions}

This is the first study by using 2D-Oxyblot analysis to investigate oxidatively modified plasma proteins in autistic children compared to healthy controls. The results showed that the carbonyl levels of two proteins (C8A and IGKC) were significantly higher in the plasma of autistic children than in healthy controls, which are found to be involved in complement system and immunoregulation. 
The results support the view that oxidative stress may be involved in the pathogenesis of autism and add additional evidence for oxidative stress in autism, implicating that antioxidant therapy may be beneficial in the treatment of autism. This study will enhance our understanding about autism pathogenesis, and if this can be replicated in larger independent and controlled trials then maybe this type of technique can be used in the future as a possible diagnostic tool.

\section{Abbreviations}

2-DE: two-dimensional gel electrophoresis; 3NT: 3-nitrotyrosine; AD: Alzheimer's disease; ASD: autism spectrum disorder; DNPH: 2,4-dinitrophenylhydrazine; IPG: immobilized pH gradients.

\section{Authors' contributions}

LMS and C-YF conceived and designed the experiments, analyzed the data and drafted the manuscript. YJC, A-CY, L-PL and K-YZ performed the experiments and help to revise manuscript. JM and LN carried out the clinical diagnosis, recruited patients and helped to revise the manuscript. J-TP and X-LM recruited patients, collected the blood samples and helped to revise the manuscript. All authors read and approved the final manuscript.

\section{Author details}

${ }^{1}$ College of Life Sciences and Oceanography, Shenzhen University, Shenzhen 518060, People's Republic of China. ${ }^{2}$ Early Childhood Development Center, Populations and Family Planning Hospital of Baoan, Shenzhen 518101, People's Republic of China.

\section{Acknowledgements}

We are grateful to Dr. Javed lqbal from Shenzhen University for critical review and helpful suggestions of the manuscript, and Shuiming Li and Yong Wang from Shenzhen University for their technical assistance.

\section{Competing interests}

The authors declare that they have no competing interests.

\section{Availability of data and materials}

Data are freely available for the readers.

\section{Consent for publication}

The authors showed their consent for publication of the research results.

\section{Ethics approval and consent to participate}

The research was approved by Human Research Ethics Committees of Populations and Family Planning Hospital of Baoan and complies with the guidelines of the Helsinki Declaration. Written informed consent for study participation was obtained from parents of children.

\section{Funding}

This study was financially supported by the Shenzhen Bureau of Science, Technology and Information (Nos. JCYJ20140418095735542, JCYJ201504023000130).

Received: 23 July 2016 Accepted: 3 January 2017

Published online: 09 January 2017

\section{References}

1. Mandic-Maravic V, Pejovic-Milovancevic M, Mitkovic-Voncina M, Kostic $M$, et al. Sex differences in autism spectrum disorders: does sex moderate the pathway from clinical symptoms to adaptive behavior? Sci Rep. 2015;5:10418.

2. Baird G, Simonoff E, Pickles A, Chandler S, et al. Prevalence of disorders of the autism spectrum in a population cohort of children in
South Thames: the Special Needs and Autism Project (SNAP). Lancet. 2006;368(9531):210-5.

3. Kim YS, Leventhal BL, Koh YJ, Fombonne E, et al. Prevalence of autism spectrum disorders in a total population sample. Am J Psychiatry. 2011;168(9):904-12.

4. Blumberg SJ, Bramlett MD, Kogan MD, Schieve LA, et al. Changes in prevalence of parent-reported autism spectrum disorder in school-aged U.S. children: 2007 to 2011-2012. Natl Health Stat Rep. 2013;2013(65):1-11.

5. Newschaffer CJ, Croen LA, Daniels J, Giarelli E, et al. The epidemiology of autism spectrum disorders. Annu Rev Public Health. 2007;28:235-58.

6. Stamou M, Streifel KM, Goines PE, Lein PJ. Neuronal connectivity as a convergent target of gene $x$ environment interactions that confer risk for autism spectrum disorders. Neurotoxicol Teratol. 2013;36:3-16.

7. Siniscalco D, Bradstreet JJ, Antonucci N. Therapeutic role of hematopoietic stem cells in autism spectrum disorder-related inflammation. Front Immunol. 2013;4:140.

8. Fernell E, Gillberg C. Autism spectrum disorder diagnoses in Stockholm preschoolers. Res Dev Disabil. 2010;31:680-5.

9. Daniels AM, Mandell DS. Explaining differences in age at autism spectrum disorder diagnosis: a critical review. Autism. 2014;18(5):583-97.

10. Bertrand J, Mars A, Boyle C, Bove F, et al. Prevalence of autism in a United States population: the Brick Township, New Jersey, investigation. Pediatrics. 2001;108(5):1155-61.

11. Al-Ayadhi L, Halepoto DM. Role of proteomics in the discovery of autism biomarkers. J Coll Physicians Surg Pak. 2013;23(2):137-43.

12. Lennicke C, Rahn J, Heimer N, Lichtenfels R, et al. Redox proteomics: methods for the identification and enrichment of redox-modified proteins and their applications. Proteomics. 2016;16(2):197-213.

13. Cocciolo A, Di Domenico F, Coccia R, Fiorini A, et al. Decreased expression and increased oxidation of plasma haptoglobin in Alzheimer disease: insights from redox proteomics. Free Radic Biol Med. 2012;53(10):1868-76.

14. Korolainen MA, Nyman TA, Nyyssönen P, Hartikainen ES, et al. Multiplexed proteomic analysis of oxidation and concentrations of cerebrospinal fluid proteins in Alzheimer disease. Clin Chem. 2007;53:657-65.

15. Sultana R, Boyd-Kimball D, Poon HF, Cai J, et al. Redox proteomics identification of oxidized proteins in Alzheimer's disease hippocampus and cerebellum: an approach to understand pathological and biochemical alterations in AD. Neurobiol Aging. 2006;27:1564-76.

16. Frustaci A, Neri M, Cesario A, Adams JB, et al. Oxidative stress-related biomarkers in autism: systematic review and meta-analyses. Free Radic Biol Med. 2012;52(10):2128-41.

17. Melnyk S, Fuchs GJ, Schulz E, Lopez M, et al. Metabolic imbalance associated with methylation dysregulation and oxidative damage in children with autism. J Autism Dev Disord. 2012;42(3):367-77.

18. Rose S, Melnyk S, Pavliv O, Bai S, et al. Evidence of oxidative damage and inflammation associated with low glutathione redox status in the autism brain. Transl Psychiatry. 2012;2:e134.

19. Conrad CC, Choi J, Malakowsky CA, Talent JM, et al. Identification of protein carbonyls after two-dimensional electrophoresis. Proteomics. 2001;7:829-34.

20. Shen L, Chen C, Yang A, Chen Y, et al. Redox proteomics identification of specifically carbonylated proteins in the hippocampi of triple transgenic Alzheimer's disease mice at its earliest pathological stage. J Proteomics. 2015;123:101-13.

21. Shen $L$, Lan Z, Sun X, Shi L, et al. Proteomic analysis of lanthanum citrateinduced apoptosis in human cervical carcinoma SiHa cells. Biometals. 2010;23(6):1179-89.

22. Xu X, Bi DC, Li C, Fang WS, et al. Morphological and proteomic analyses reveal that unsaturated guluronate oligosaccharide modulates multiple functional pathways in murine macrophage RAW264.7 cells. Mar Drugs. 2015;13(4):1798-818.

23. Yamaura K, Kuwata K, Tamura T, Kioi Y, et al. Live cell off-target identification of lapatinib using ligand-directed tosyl chemistry. Chem Commun. 2014:50(91):14097-140100.

24. Magherini F, Abruzzo PM, Puglia M, Bini L, et al. Proteomic analysis and protein carbonylation profile in trained and untrained rat muscles. $J$ Proteomics. 2012;75(3):978-92.

25. Anderson NL, Anderson NG. The human plasma proteome. Mol Cell Proteomics. 2002;1:845-67. 
26. Li H, Li G, Zhao X, Wu Y, et al. Complementary serum proteomic analysis of autoimmune hepatitis in mice and patients. J Transl Med. 2013;11:146.

27. Chauhan A, Chauhan V. Oxidative stress in autism. Pathophysiology. 2006;13(3):171-81.

28. Palmieri L, Persico AM. Mitochondrial dysfunction in autism spectrum disorders: cause or effect? Biochim Biophys Acta (BBA) Bioenerg. 2010;1797(6-7):1130-7.

29. Sögüt S, Zoroğlu SS, Ozyurt H, Yilmaz HR, et al. Changes in nitric oxide levels and antioxidant enzyme activities may have a role in the pathophysiological mechanisms involved in autism. Clin Chim Acta. 2003;331(1-2):111-7.

30. Juurlink BH, Paterson PG. Review of oxidative stress in brain and spinal cord injury: suggestions for pharmacological and nutritional management strategies. J Spinal Cord Med. 1998;21(4):309-34.

31. Erden-Inal M, Sunal E, Kanbak G. Age-related changes in the glutathione redox system. Cell Biochem Funct. 2002;20(1):61-6.

32. Corbett BA, Kantor AB, Schulman H, Walker WL, et al. A proteomic study of serum from children with autism showing differential expression of apolipoproteins and complement proteins. Mol Psychiatry. 2007:12(3):292-306

33. Taurines R, Dudley E, Conner AC, Grassl J, et al. Serum protein profiling and proteomics in autistic spectrum disorder using magnetic bead-assisted mass spectrometry. Eur Arch Psychiatry Clin Neurosci. 2010;260(3):249-55.

34. Oberholzer A, Oberholzer C, Moldawer LL. Sepsis syndromes: understanding the role of innate and acquired immunity. Shock. 2001;16(2):83-96.

35. Onore C, Careaga M, Ashwood P. The role of immune dysfunction in the pathophysiology of autism. Brain Behav Immun. 2012;26(3):383-92.
36. Heuer L, Ashwood P, Schauer J, Goines P, et al. Reduced levels of immunoglobulin in children with autism correlates with behavioral symptoms. Autism Res. 2008;1(5):275-83.

37. Xu N, Li X, Zhong Y. Inflammatory cytokines: potential biomarkers of immunologic dysfunction in autism spectrum disorders. Mediators Inflamm. 2015;2015:531518.

38. Kleinveld HA, Sluiter W, Boonman AM, Swaak AJ, et al. Differential stimulation by oxygen-free-radical-altered immunoglobulin $\mathrm{G}$ of the production of superoxide and hydrogen peroxide by human polymorphonuclear leucocytes. Clin Sci. 1991;80:385-91.

39. Rasheed Z. Hydroxyl radical damaged immunoglobulin $\mathrm{G}$ in patients with rheumatoid arthritis: biochemical and immunological studies. Clin Biochem. 2008:41:663-9.

40. Ahmed S, Gibbons N, Mattana J. Oxidized immunoglobulin G in patients with end-stage renal disease treated by hemodialysis. Ann Clin Lab Sci. 2003:33:11-7.

41. Tripathi T, Rasheed Z. The oxidative by-product, hydroxyl radical, damaged immunoglobulin-G in patients with non-insulin dependent diabetes mellitus. Bratisl Lek Listy. 2010;111:477-84.

42. Rasheed Z, AI-Shobaili HA, Alzolibani AA, Ismail Khan M, et al. Immunological functions of oxidized human immunoglobulin $\mathrm{G}$ in type 1 diabetes mellitus: its potential role in diabetic smokers as a biomarker of elevated oxidative stress. Dis Markers. 2011;31(1):47-54.

43. Shen $L$, Chen $Y$, Yang A, Chen C, et al. Redox proteomic profiling of specifically carbonylated proteins in the serum of triple transgenic Alzheimer's disease mice. Int J Mol Sci. 2016;17(4):469.

44. Margiloff L, Chaplia L, Chow A, Singhal PC, et al. Metal-catalyzed oxidation of immunoglobulin $\mathrm{G}$ impairs Fc receptor-mediated binding to macrophages. Free Radic Biol Med. 1998:25:780-5.

\section{Submit your next manuscript to BioMed Central and we will help you at every step:}

- We accept pre-submission inquiries

- Our selector tool helps you to find the most relevant journal

- We provide round the clock customer support

- Convenient online submission

- Thorough peer review

- Inclusion in PubMed and all major indexing services

- Maximum visibility for your research

Submit your manuscript at www.biomedcentral com/submit
O Biomed Central 